\title{
The Role of Threat in the Human Empowerment Sequence
}

\author{
-Kris Dunn, School of Politics and International Studies, University of Leeds \\ -Viktoria Spaiser, School of Politics and International Studies, University of Leeds \\ -Harvey Dodds, School of Social Sciences and Humanities, Loughborough University
}

\begin{abstract}
Recent work by Dunn et al. (2017) proposes an integration of two normally disparate fields of research: political culture and individual-level authoritarianism. This proposal notes a remarkable similarly between Welzel's (2013) concept of emancipative values and the values-oriented conceptualization of authoritarianism proposed by Feldman and Stenner (1997). Dunn at al. provide some rudimentary empirical evidence that authoritarianism can be productively integrated into Welzel's "human empowerment sequence" but due to data limitations are unable to examine what they see as one of the most important benefits of this integration: the interaction between authoritarianism and threat in predicting emancipative attitudes. The sixth wave of the World Values Survey provides the previously unavailable data (a measure of perceived threat) and allows us to examine whether authoritarianism interacts with threat to affect the expression of social and political attitudes. Analysis of this data supports those expectations derived from the authoritarianism literature and provides further support for Dunn et al.'s proposal.
\end{abstract}

KEYWORDS: authoritarian predisposition; libertarian predisposition; modernization theory; human empowerment sequence; perceived threat 
In a recent article, Dunn, Griffiths, Lamb, Shortt, and Theochari (2017) suggest interlacing research from the political culture and individual-level authoritarianism literatures. Dunn et al. argue that these two literatures contain theories that overlap on some of their core concepts and that by integrating these theories we could combine the rich collection of findings contained in both literatures. This article builds on Dunn et al.'s initial proposal by analyzing data to examine a hypothesis that was untestable with the data used in that piece of research: that perceived threat moderates the relationship between authoritarianlibertarian value orientations and emancipative attitudes.

In the discipline of Political Science, the political culture literature primarily aims to explain the rise of democracy. One prominent line of research in this literature began by considering value shift over generations and using this shift to explain the rise of democracy, first in the West and then elsewhere (Inglehart, 1971, 1977, 1988, 1990, 1997, 2017). The initial focus in this research was on post-materialist values; how those raised in societies that had attained a high level of existential security, and could take such for granted, could move beyond a narrow focus on materialist values, those values concerned with meeting basic existential needs, to develop post-materialist values concerned with achieving goals that look beyond the acquisition of existential security to more psychosocial needs, such as social and political liberty. This shift from survival-oriented to self-actualizing-oriented values encourages an increased liberal-democratic outlook on many aspects of life, including governance.

In the discipline of Psychology, authoritarianism was conceived to explain the recession of democracy in Europe following World War I. In a recent conceptualization, Feldman and Stenner (Feldman, 2003; Feldman \& Stenner, 1997; Stenner, 2005) describe authoritarianism as a values orientation concerned with the individual weighting of social conformity values against individual autonomy values. This orientation interacts with 
perceived threat to predict attitudes toward authority and outgroups; attitudes with direct relevance to support for or opposition to liberal-democratic institutions and governance.

The intersection of these two literatures is clear. Both are concerned with the development and functioning of societies under liberal-democratic governance and both are concerned with the development and consequences of value orientations. Dunn et al. (2017) point to the benefits that can be derived from integrating these two literatures. One of the predominant benefits, they suggest, is that an integrated theory is better able to consider how perceived threat can affect the translation of political culture, in terms of values, into the expression of attitudes and behavior. Using data from the $6^{\text {th }}$ wave of the World Values Survey, this research explicitly examines the relationship between authoritarianism, as a values-orientation, and emancipative 'attitudes', looking specifically into the moderating effect perceived threat exerts on this relationship.

Considering threat and value-attitude congruence, or lack thereof, is particularly relevant in light of current discussions regarding the health and stability of liberal-democratic institutions (Halikiopoulou \& Vasilopoulou, 2016; McCoy, Rahman, \& Somer, 2018; Norris \& Inglehart, 2019). Within the political culture literature, the congruence thesis (Almond \& Verba, 1963), states that political institutions must reflect the values that are dominant in the political culture if they are to remain stable. If this reflection is distorted, if political institutions are reflective of values that substantively differ from those of the political culture, those institutions will be unstable. If it is congruence between popular and institutional values that is central to the stability of political institutions, then any temporary attitudinal shift occurring in response to temporary conditions that impact people's sense of security (e.g., natural disasters, economic recessions, terrorist attacks) should not destabilize established political institutions. In other words, temporary attitudinal shifts that are a response to temporary perceived threat should not threaten institutional stability; only enduring attitudinal 
shifts that occur as a reflection of enduring value change should destabilize institutions. As such, while we should by no means be complacent when liberal-democratic norms seem to come under attack from the expression of democratic norm-incongruent attitudes, we should be wary to not over-respond to shifts in public opinion when these shifts follow on the tail of temporary crises.

\section{The Human Empowerment Sequence}

Building on previous adaptations of Modernization Theory (Inglehart \& Welzel, 2005), Welzel's (2013) Human Empowerment Sequence explains the process that provides individuals with the capability and motivation to attain and exercise individual freedoms and rights. The sequence begins with the individual and societal attainment of "action resources" resulting from social and economic development. Action resources fall into three categories: material (i.e., resources that concretely exist and have practical uses, such as equipment and money), intellectual (i.e., information and skills that enable greater exploitation of material resources), and connective (i.e., networks that facilitate the exchange of both material and intellectual resources). An abundance of material resources ensures the fulfilment of basic physiological needs and existential security. This security provides individuals with the motivation to look beyond immediate physiological requirements and towards personal developmental and self-actualizing goals. Surplus material resources, those that exceed what are required for existential security, are invested in ways that increase both intellectual and connective resources through educational enhancement and technological innovation. Thus, greater existential security motivates a shift from prioritizing those values that focus on and facilitate existential security, to those that focus on and facilitate psychosocial wellbeing. These values are termed "emancipative values" by Welzel and are defined as a set of values that promote individual autonomy, respect for individual choice, expression of voice, and equality of opportunity. As greater development provides greater numbers of individuals with 
access to action resources, emancipative values increasingly permeate society through various institutions, legislation, art, philosophy, public opinion, and so on.

\section{The Authoritarian Dynamic}

The authoritarianism literature arose from the desire to understand how democracy could devolve into authoritarianism; to understand why democratic citizens would seemingly seek to create a less democratic state. The concept of authoritarianism is the answer to this question: there are simply some people in any given society that prefer authoritarian forms of governance. Those whose attitudes, beliefs, values, or personality suggest a preference for authoritarian forms of governance were labelled authoritarians.

The authoritarian, as first described by Fromm (1941), was explained to be a person who, due to tensions between having the freedom to express the self without having the capability to do so, retreats into sadomasochistic relationships that they believe will provide respite from their insecurities. This character-type had no proposed opposite; it was simply a description of one of a number of maladaptive responses to a stressful social environment.

This description of the authoritarian was quickly supplanted by another psychoanalytic description that focused more on familial developmental processes. Adorno, Frenkel-Brunswik, Levinson, and Sanford (1950) argued that overly harsh and punitive childrearing practices lead to the development of an authoritarian personality expressed through nine co-varying attitudinal clusters: conventionalism, authoritarian submission, authoritarian aggression, anti-intraception, superstition and stereotypy, power and toughness, destructiveness and cynicism, projectivity, and sex. Unlike Fromm's conceptualization, the authoritarian personality, also referred to as the anti-democratic personality (FrenkelBrunswik, Levinson, \& Sanford, 1947), had an implied opposite: the democratic personality. 
This conceptualization, though highly influential, was subject to numerous critiques and was eventually adjusted to fall in line with a more behavioral, and less psychoanalytic, paradigm (Altemeyer, 1981, 1988, 1996). Similar to Adorno et al. (1950), Altemeyer suggested that authoritarianism is an attitudinal expression of personality. Altemeyer, though, changed the causal focus from family-focused socialization processes to socialization processes more generally and whittled Adorno et al.'s list of attitudinal clusters down to what he argues are the three core clusters: conventionalism, authoritarian submission, and authoritarian aggression. Though these echo Fromm's (1941) conceptualization of authoritarianism as a sadomasochistic striving - the need to feel secure through submission to a dominant power and through the ability to dominate or destroy anything or anyone that threatens to violate the security that power provides - Altemeyer avoided the more psychoanalytic assumptions of this earlier research in favor of a more behavioralist interpretation of these clusters as resulting largely from social learning processes.

The most recent adjustment to the concept of authoritarianism aimed to act as a conceptual and empirical curative to endogeneity problems between authoritarianism and those constructs it aims to explain (Feldman \& Stenner, 1997); to disentangle intolerance from authoritarianism. This revision conceptualizes authoritarianism as a values orientation concerned with the relative preference for social conformity over individual autonomy (Feldman, 2003; Stenner, 2005) and is intended to be predictive of authoritarian attitudes, including those often used to measure the concept itself (such as Altemeyer's (1996) Rightwing Authoritarianism Scale). This values-oriented conceptualization suggests a scale anchored at one end by those who strongly favor social conformity and have no regard for individual autonomy and at the other end by those who strongly favor individual autonomy and have no regard for social conformity; those in the exact middle of the scale possess an equal preference for both individual autonomy and social conformity. Any given individual is 
more or less authoritarian (or more or less libertarian if one prefers using the opposite pole as the reference category) depending on their relative preference for social conformity or individual autonomy. Those across this scale are expected to express attitudes that are generally expressive of and consistent with their location on this scale. This values orientation, then, inclines (predisposes) an individual toward certain attitudes. However, through dynamic interactions with environmental stimuli, an individual's predisposition, the 'default' expression of their values orientation, can be overridden by situational pressures particularly in the face of perceived threat.

Building on and somewhat adjusting Feldman and Stenner's earlier work on this dynamic process, Hetherington and Weiler (2009) suggest that when we perceive threat, we all respond in nearly identical fashion: we express more authoritarian attitudes. Contrary to Stenner (2005), they argue that the more authoritarian are particularly sensitive to threat and are more likely to feel threatened as a matter of course, even in the absence of any objectively identifiable threat - a situation that may result from the broader social and political environment (Dunn, 2014; Dunn \& Singh, 2014; Singh \& Dunn, 2013, 2015). Hetherington and Weiler (2009) argue that this general sense of threat is why the more authoritarian are prone to holding and expressing more authoritarian attitudes (relative to the more libertarian) even when reporting feeling minimal threat from specific stimuli.

That the more authoritarian are more prone to feeling threatened even in the absence of any specific threat results in limited movement potential on measures of authoritarian attitudes. For the more libertarian, however, there is a good deal more room for expressed attitudinal change. Hetherington and Weiler (2009) demonstrate that when the more libertarian perceive a threat, they become less supportive of civil liberties and rights, more intolerant of difference, more supportive of perceived authority, and more supportive of force 
exercised by such authority. In other words, they adopt an attitudinal profile similar to that of authoritarians.

\section{Integration of Authoritarianism into the Human Empowerment Sequence}

Dunn et al. (2017) argue that there is significant conceptual overlap between Welzel's survival-emancipative values and the authoritarianism-libertarianism concept and, on this basis, suggest that the Human Empowerment Sequence (HES) is more thoroughly explained if the concept of authoritarianism replaces emancipative values. There are three key aspects to Dunn et al.'s (2017) argument: first, regarding how values are defined and measured; second, regarding theoretical overlap between the two literatures; and third, regarding the conceptual overlap between the survival-emancipative and authoritarian-libertarian values orientations.

First, Dunn et al. (2017) argue that Welzel (2013) understands (emancipative) values to be malleable and transient and thus definitionally inconsistent with the current understanding of the concept: the wider literature, they argue, places emphasis on the relative stability and trans-situational nature of values (e.g., Hitlin \& Piliavin, 2004) as opposed the more malleable nature of attitudes (e.g., Banaji \& Heiphetz, 2010). This feeds into their critique that Welzel's measure of 'emancipative values' is more appropriately labeled 'emancipative attitudes' as many of the items Welzel uses to construct his measure more likely express attitudes rather than values.

There is also concern that Welzel's (2013) measure does not translate well across cultures. While Dunn et al. (2017) report that the cross-cultural validity of the emancipative values measure is quite controversial (e.g., Alemán \& Woods, 2016; Welzel \& Inglehart, 2016), recent research has provided more critical evidence and argumentation against the continued use of this measure in cross-cultural research (Sokolov, 2018). 
Second, there is substantial theoretical and empirical overlap between the HES and the authoritarianism literature - something also recently noted by Inglehart (2017). Both theories argue that resources affect value development. This a central tenet of the HES. It is also a common theme within the authoritarianism literature. Fromm (1941) argued that a fundamental cause of the tension between 'freedom from' and 'freedom to', the tension that leads to the development of the authoritarian character, is a lack of resources necessary to engage in those pursuits that allow the person to fully develop as an individual. Lipset (1959) similarly connected authoritarianism to a lack of resources noting that authoritarians exhibited "low education, low participation in political organizations or in voluntary organizations of any type, little reading, isolated occupations, [and] economic insecurity"; each of these characteristics can be easily placed into Welzel's (2013) three classes of action resources. This is also supported by Dunn et al.'s (2017) analysis of action resources and authoritarianism/libertarianism; greater levels of resource availability correspond with a more libertarian, and less authoritarian, predisposition.

Third, the conceptual overlap between survival-emancipative and authoritarianlibertarian values, though not precise, is considerable. Both orientations focus on the relative weight of values that either inhibit or promote increased control over one's life. Three aspects under the emancipative values umbrella - autonomy, choice, and voice - can all be considered aspects of individual autonomy. The fourth aspect, equality of opportunity, is conceptually distinct from the others and may be an overreach in the emancipative values scale in that two distinct value sets, autonomy and equality (cf., Schwartz, 2012), are integrated into a single construct.

There are further benefits to integrating these two literatures. As each literature has tended to focus on relatively distinct aspects of value development and consequences, their integration will potentially prove quite enlightening; as Dunn et al. (2017) summarily note: 
"uniting these literatures provides the modernization literature with a more nuanced understanding of individual-level processes, and the authoritarianism literature with a more expansive consideration of the causes and consequences of authoritarianism."

Dunn et al. (2017) thus provide an important adjustment to Welzel's (2013) work as greater integration of individual differences into the Human Empowerment Sequence results in a richer and more dynamic model. This is because, on its own, Welzel's theory suggests our values are contingent on resource abundance or scarcity, however, Dunn et al.'s adjustment shows that perceived threat - which does not necessarily entail tangible effects on resources - can play a significant role in determining our attitudes. Greater emphasis on "anxiety based values" has been found following terror attacks (Verkasalo, Goodwin, \& Bezmenova, 2006), political assassinations (Raviv, Sadeh, Raviv, Silberstein, \& Diver, 2000), and economic crises (Sortheix, Parker, Lechner, \& Schwartz, 2017), and among recent immigrants (Lönnqvist, Jasinskaja-Lahti, \& Verkasalo, 2011). These effects on value expressions are often, though not always, temporary, with a bounce-back effect seeing such expressions returning to previous states after the crisis has passed. This bounce-back effect suggests that after perceived threat has faded, the libertarian predisposition reasserts its impact on value-relevant expressions, thus accounting for temporary attitudinal changes alongside the general stability of values.

Of particular importance to issues regarding value development, stability, and change, bounce-back effects are not guaranteed. Sortheix et al.'s (2017) study on the Global Financial Crisis indicated that some effects of the crisis on the subjects waned over time while others appeared to be more permanent. This is, perhaps, because the study looked exclusively at adolescents - individuals whose values are still in the process of formation - and also because for many Europeans, the effects of the financial crisis are still ongoing (Eurofound, 2017; Institute for Fiscal Studies, 2017). A more permanent effect was also observed among 
Israeli adolescents during war, though the researchers conceded that if data was collected over a longer time period, a bounce-back effect may have manifested (Daniel, Fortuna, Thrun, Cioban, \& Knafo, 2013).

Given the conceptual similarities between emancipative and libertarian valuesorientations and the support from existing literature regarding the role of threat on political attitudes and behavior, Dunn et al.'s (2017) adjustment to Welzel's (2013) HES seems potentially fruitful. Their initial research provides a base level of support for this adjustment, but much was left unanswered due to data limitations in the fifth wave of the World Values Survey. One rather important element of their theory that Dunn et al. (2017) were unable to address was whether threat does indeed moderate the connection between libertarian valueorientations and those attitudes demonstrated to be relevant to democratic development: Welzel's (2013) emancipative attitudes. In the following analyses, we make use of data from the sixth wave of the World Values Survey (Inglehart et al., 2014) - the first wave of the survey to ask respondents about their perception of threat - to address this particular gap.

\section{Hypotheses}

Dunn et al. (2017) argue that there should be a negative interaction between authoritarianism and threat when predicting emancipative attitudes; while emancipative attitudes should demonstrate little variation across the range of threat for the more authoritarian, for the more libertarian, emancipative attitudes should be notably weaker where perceived threat is greater (cf., Hetherington \& Weiler, 2009). Specifically, they argue for the following set of hypotheses regarding the relationship between the libertarian predisposition, threat, and emancipative attitudes. To maintain consistency with Dunn et al. (2017), we reference the authoritarian-libertarian continuum by its libertarian pole. Additionally, due to measurement issues that we discuss below, we focus on the set of sub-indices that make up the emancipative attitudes index instead of on the full index. 
$\mathrm{H}_{1}$ : The libertarian predisposition will be positively correlated with the emancipative attitudes sub-indices.

$\mathrm{H}_{2}$ : The relationship between the libertarian predisposition and the emancipative attitudes sub-indices will be weaker when perceived threat is greater.

$\mathrm{H}_{3}$ : Those with a low libertarian predisposition (i.e., the more authoritarian) will exhibit similar scores on the emancipative attitudes sub-indices regardless of perceived threat.

$\mathrm{H}_{4}$ : Those with a high libertarian predisposition and who perceive greater threat will express lower scores on the emancipative attitudes sub-indices than will those with a similar predisposition and a lower perception of threat.

\section{Method}

\section{Sample}

The data utilized in the following analyses is drawn from wave 6 of the World Values Survey and Freedom House's Freedom in the World reports.

The WVS draws a representative sample of at least 1000 respondents between the ages of 18 and 85 for each country involved in the study. Full probability sampling is done where resources allow; otherwise, strictly governed quota sampling, or some combination of both, is used. Interviews are conducted face-to-face. Every reasonable effort is made to reduce non-response. The $\mathrm{WVS}_{6}$ surveys 60 countries from around the globe between the years 2010 to 2014. Missing relevant data reduces the sample used here to 54 countries and 62,924 individuals. $^{1}$

\footnotetext{
${ }^{1}$ Colombia, Egypt, Haiti, Kuwait, Qatar, and Uzbekistan are dropped from the analyses due to missing data.
} 


\section{Measures}

Emancipative attitudes sub-indices: A recent analysis of the emancipative values scale found the full scale to be non-invariant across countries and the sub-indices to be non-distinct (Sokolov, 2018). Further analyses demonstrated that the only sub-index that may be crossnationally invariant is the choice index (Sokolov, 2018). Due to Sokolov's analyses, we have chosen to focus on the sub-indices instead of the full scale. However, rather than ignoring the three non-invariant sub-indices, we have opted to examine the relationship between libertarianism and all four of the sub-indices and leave it to the reader to decide the validity and relevance of the analyses for the three non-invariant sub-indices.

The emancipative attitudes sub-indices are constructed according to Welzel (2013, online appendix). ${ }^{2}$ The four sub-indices are labelled autonomy, choice, equality, and voice. The autonomy sub-index indicates a respondent's preference for specific qualities that children can be encouraged to learn at home: imagination, independence, and obedience. The choice sub-index indicates how justifiable a respondent believes abortion, divorce, and homosexuality are. The equality sub-index indicates whether a respondent believes that males should receive priority over females in job placements, university places, and political leadership. The voice sub-index indicates how important a respondent considers having a say in her/his community, job, government's decisions, and in general. Each sub-index ranges from 0 to 1 with a higher value indicating a greater orientation toward autonomy, choice, equality, and voice, respectively.

Libertarianism: Dunn et al. (2017) define libertarianism to be a values orientation concerned with the relative weighting of individual autonomy values against social conformity values. To measure this concept they construct a scale using items from

\footnotetext{
${ }^{2}$ The online appendix can be found at: www.cambridge.org/gb/download_file/473755/.
} 
Schwartz's (2012) “motivational continuum" of values. The lead in question to these items asks: "Now I will briefly describe some people. Using this card, would you please indicate for each description whether that person is very much like you, like you, somewhat like you, not like you, or not at all like you?" The response categories range from 1 (very much like me) to 6 (not at all like me). ${ }^{3}$ The hedonism, stimulation, and self-direction values items are averaged to produce the Openness to Change scale. The security, conformity, and tradition values items are averaged to produce the Conservation scale. The wording for these 6 items is provided in Table 1. The Openness to Change scale is intended to represent individual autonomy values. The Conservation scale is intended to represent social conformity values. To measure libertarianism, Dunn et al. (2017) subtract the Conservation scale from the Openness to Change scale. Our analyses of this measure, however, indicate that the 3 -item openness to change and the 3-item conservation sub-indices are non-invariant across countries. $^{4}$

Table 1: WVS items used to construct the libertarianism scale

\begin{tabular}{|c|c|c|}
\hline Value & IVS Label & alue Wording \\
\hline Self-direction & V70 & $\begin{array}{l}\text { It is important to this person to think up new ideas and be creative; to do } \\
\text { things one's own way. }\end{array}$ \\
\hline Security & V72 & $\begin{array}{l}\text { ving in secure surroundings is important to this person; to avoid anything } \\
\text { hat might be dangerous. }\end{array}$ \\
\hline Hedonism & V73 & $\begin{array}{l}\text { It is important to this person to have a good time; to "spoil" oneself. } \\
\text { Adventure and taking risks are important to this person; to have an exciting }\end{array}$ \\
\hline Stimulation & & $\begin{array}{l}\text { life. } \\
\text { It is important to this person to always behave properly; to avoid doing }\end{array}$ \\
\hline Conformity & V77 & anything people would say is wrong. \\
\hline Tradition & V79 & one's religion or family. \\
\hline
\end{tabular}

\footnotetext{
${ }^{3}$ The reader might notice the divergence in the number of categories listed in the question (5) and the number of possibly responses implied by the range of the variable (6). This is due to the question wording missing response category 4: "A little like me". This falls between "Somewhat like me" and "Not like me".

${ }^{4}$ The model-fit indices for a Confirmatory Factor Analysis model with the three items for openness to change and the three items for conservation were Chi-Square $=2957.241, \mathrm{CFI}=0.924, \mathrm{TLI}=0.857, \mathrm{RMSEA}=0.080$, $S R M R=0.035$. The Modification Indices suggested removing the hedonism and security items from the model to improve the model fit.
} 
Following Feldman (2003), we construct our measure using only the stimulation and self-direction items for the individual autonomy scale and only the conformity and tradition items for the social conformity scale. The individual autonomy index is produced by averaging the stimulation and self-direction items. A higher score on this index indicates a greater identification with individual autonomy values. The social conformity index is produced by averaging the conformity and tradition items. A higher score on this index indicates a greater identification with social conformity values. The libertarianism scale is created by subtracting the social conformity index from the individual autonomy index, thereby creating a scale that ranges from -5 to +5 . Negative scores indicate an increasing preference for social conformity over individual autonomy. Positive scores indicate an increasing preference for individual autonomy over social conformity. A score of 0 suggests either indifference or ambivalence (cf., Kaplan, 1972).

To test our assumption that the latent variable structure holds for the various countries in the data, we conducted a series of model analyses. We first estimated a baseline Confirmatory Factor Analysis (CFA) that does not account for the multi-group structure of the data. We then compared this to a Multi-Group Confirmatory Factor Analysis (MGCFA) that does take account of the multi-level nature of the data. While the configural invariance model does not fit as well as the baseline model, the model-fit indices indicate that the configural invariance model fits the data well and that accounting for the multi-group structure of the data in the model does not drastically reduce model fit. Unsurprisingly, as metric invariance is quite difficult to obtain across so many different countries (cf., Davidov, Meuleman, Cieciuch, Schmidt, \& Billiet, 2014), we were unable to confirm metric invariance. The metric invariance model was of significantly poorer fit to the data, relative to the configure invariance model. We were unable to confirm or reject partial metric invariance 
as the two indices consist of only two items each, leaving no room for partial restrictions and freeing specific item loadings.

While we were unable to confirm equal factor loadings across countries (metric invariance), our analyses do confirm the overall factor structure holds up similarly for different groups (configural invariance). Previous research has noted the centrality of configural invariance as the prime consideration in cross-group analyses as this indicates that we are indeed measuring the same latent variable(s) in the different groups (Steenkamp \& Baumgartner, 1998). Consequently, we can assume that both the individual autonomy and social conformity values scales are similar across various countries; cross-country comparisons are thereby permissible.

\begin{tabular}{|c|c|c|c|c|c|c|}
\hline \multirow{2}{*}{ Model Fits } & \multicolumn{3}{|c|}{ Libertarianism } & \multicolumn{3}{|c|}{ Threat } \\
\hline & $\begin{array}{l}\text { Configural } \\
\text { Invariance }\end{array}$ & $\begin{array}{l}\text { Metric } \\
\text { Invariance }\end{array}$ & $\begin{array}{l}\text { Partial Metric } \\
\text { Invariance }\end{array}$ & $\begin{array}{l}\text { Configural } \\
\text { Invariance }\end{array}$ & $\begin{array}{l}\text { Metric } \\
\text { Invariance }\end{array}$ & $\begin{array}{l}\text { Partial Metric } \\
\text { Invariance }\end{array}$ \\
\hline Chi-Square & 292.312 & 2586.152 & - & 1072.851 & 8658.120 & 3362.217 \\
\hline $\mathrm{CFI}$ & 0.987 & 0.873 & - & 0.993 & 0.938 & 0.957 \\
\hline \multirow[t]{2}{*}{ RMSEA } & 0.064 & 0.090 & - & 0.064 & 0.155 & 0.090 \\
\hline & \multicolumn{3}{|c|}{$\begin{array}{l}\text { Baseline Model: } \\
\text { Chi-Square: } 28.136 \\
\text { CFI: } 0.998 \\
\text { RMSEA: } 0.021\end{array}$} & \multicolumn{3}{|c|}{$\begin{array}{l}\text { Baseline Model: } \\
\text { Chi-Square: } 470.092 \\
\text { CFI: } 0.995 \\
\text { RMSEA: } 0.055\end{array}$} \\
\hline
\end{tabular}

CFI: Comparative Fit Index; RMSEA: Root Mean Square Error of Approximation

Threat: Though it is currently unclear what type of threat is most important to consider as a potential moderator between libertarianism and attitudes, due to what is on offer in the $\mathrm{WVS}_{6}$, we focus on what can broadly be considered to be existential threats: situations which threaten the physical security of the individual and/or the individual's ingroup.

The WVS6 includes a battery of items asking respondents how worried they are about 6 specific threats: loosing or not finding a job, not being able to give their children a good education, war involving their country, a terrorist attack, a civil war, and the government 
wiretapping or reading their mail or email. There are four response categories: not at all; not much; a good deal; very much.

Measurement invariance analyses indicate that a model consisting of all 6 threat items does not fit the data particularly well; specifically, the job security and children's education items seem to inhibit establishing measurement invariance. ${ }^{5}$ We therefore removed these two items from consideration. Similarly to the procedure explained above for libertarianism, we compared the four-item configural invariance model first to a baseline four-item CFA model and found that it fit the data sufficiently well. Compared to the configural invariance model, the metric invariance model demonstrated a significantly poorer fit (see Table 2): a large difference between the two Chi-Squares, a CFI below 0.95 and RMSEA above 0.1. Based on the Modification Indices results we allowed the factor loadings for the threat of civil war and surveillance threat items to vary across countries, leaving the two remaining items, threat of war and threat of terror attack, restricted. As shown in Table 2, the model fit indices for the partial metric invariance model are considerably better than the full metric invariance model; and in comparison to the configural invariance model, the model still fits the data well. This level of invariance supports our assumption that this measure is comparable across countries and is acceptable to use in our analyses, as explained above for libertarianism.

The threat index averages the above-noted four items. We rescale the threat measure to range from 0 to 1 , with higher scores indicating a greater level of perceived threat.

Control variables: Following Dunn et al. (2017), our analyses control for basic demographics: age, education, income, and sex. Age is a report of the respondent's age adjusted so that 18 years old corresponds to 0 (i.e., age $=$ reported age -18 ). This rescaled

\footnotetext{
${ }^{5}$ The model-fit indices for a CFA model with the six threat items were Chi-Square $=16054.232, \mathrm{CFI}=0.920, \mathrm{TLI}$ $=0.866, \mathrm{RMSEA}=0.175, \mathrm{SRMR}=0.065$. The Modification Indices suggested removing job security threat and threat to children's education from the model to improve the model fit.
} 
age variable ranges from 0 to 81 . Education is a variable resulting from a question inquiring in to the respondent's highest level of education; recoded to range from 0 (no formal education) to 6 (university-level education, with degree). Income is a measure of the respondent's income level in terms of country-specific income categories; ranging from 0 to 9 with a higher number indicative of a higher level of income. Sex is coded by the interviewer as male (0) or female (1) based on her/his observation of the respondent.

\section{Results}

The following analyses are conducted using multi-level linear regression models with individuals grouped within countries. Specifically, we run a multilevel random effects model utilizing the xtreg command with the re option in STATA 13. We run a multilevel model to account for the non-independence of observations across countries (cf., Hox, Moerbeek, \& Schoot, 2018). Intercept-only models of the four dependent variables demonstrate that a substantial portion of the variance of these four indices is due to country-level differences: $13.7 \%$ of the variance of the autonomy variable is explained by country-level differences as is $38.5 \%$ of the choice variable, $27.5 \%$ of the equality variable, and $13.3 \%$ of the voice variable. Demonstrating country-level effects on the dependent variables evidences that within-country observations are not independent of one-another, confirming a hierarchical data structure and justifying the use of a multilevel model.

We choose a random effects model as we assume a distribution of true effects, as opposed to a single true effect with any variation a result of within-country estimation error. Assuming a distribution of true effects indicates that the effect of libertarianism on the dependent variables is neither fixed across countries nor solely and equally conditioned by our particular measure of threat. Given theory on authoritarianism, we expect the political and social situation may also influence how libertarianism affects the dependent variables (cf., Dunn, 2014; Dunn \& Singh, 2014; Singh \& Dunn, 2013, 2015). For example, a more 
conflict-ridden society may mean less perceived threat is required to push the more libertarian toward embracing less emancipative attitudes; or less threat may be required in a country with a more authoritarian culture as authoritarian attitudes are more widely held and acceptable. As such, even if all measures were perfect representations of their associated concepts and we had a perfectly representative sample, we would not expect the results for all countries to be identical. These expectations suggest we utilize a multilevel, random effects model.

We report our analyses separately for each dependent variable starting with autonomy.

\section{Autonomy}

$\mathrm{H}_{1}$ predicts a positive relationship between libertarianism and autonomy. Model A in Table 3 speaks to this relationship. In Model A, we regress autonomy on libertarianism controlling for threat, age, education, sex (female), and income. Aligning with the predictions of $\mathrm{H}_{1}$, as the value of libertarianism increases, so too does the value of autonomy. Those who report the lowest score on the libertarianism variable (-5) are predicted to score 0.22 points (22\% of the autonomy scale) less than those with the highest score $(+5)$.

Building on this, Model B in Table 3 provides evidence for $\mathrm{H}_{2} . \mathrm{H}_{2}$ predicts that the relationship between a libertarian predisposition and autonomy will be weaker when threat is greater; i.e., the interaction between libertarianism and threat will negatively predict autonomy. The coefficient on the interaction listed in Model B reports a negative coefficient, indicating that the slope on libertarianism decreases as threat increases. Examining the slope on authoritarianism over the range of threat, reported in Table 4, confirms this: higher reported levels of threat correspond with a gentler slope on libertarianism. The slope at the lowest level of threat is 0.031 , corresponding to an increase of $31 \%$ of the range of the 
autonomy scale. The slope at the highest level of threat is 0.016 , indicating an increase of $16 \%$ of the range of the autonomy scale.

\begin{tabular}{|c|c|c|c|c|c|c|}
\hline & \multicolumn{3}{|c|}{ model A } & \multicolumn{3}{|c|}{ model B } \\
\hline & $\beta$ & S.E. & p-value & $\beta$ & S.E. & $p$-value \\
\hline libertarianism & 0.022 & 0.001 & 0.000 & 0.031 & 0.002 & 0.000 \\
\hline threat & -0.019 & 0.004 & 0.000 & -0.028 & 0.004 & 0.000 \\
\hline libertarianism $X$ threat & -- & -- & -- & -0.016 & 0.002 & 0.000 \\
\hline age & 0.000 & 0.000 & 0.000 & 0.000 & 0.000 & 0.000 \\
\hline education & 0.013 & 0.001 & 0.000 & 0.013 & 0.001 & 0.000 \\
\hline female & 0.000 & 0.002 & 0.966 & 0.000 & 0.002 & 0.977 \\
\hline income & 0.004 & 0.001 & 0.000 & 0.004 & 0.001 & 0.000 \\
\hline constant & 0.420 & 0.012 & 0.000 & 0.425 & 0.012 & 0.000 \\
\hline n (countries) & 54 & & & 54 & & \\
\hline average $\mathrm{n}$ (individuals) per country & 1165.3 & & & 1165.3 & & \\
\hline$r^{2}$ within & 0.012 & & & 0.026 & & \\
\hline$r^{2}$ between & 0.196 & & & 0.228 & & \\
\hline$r^{2}$ overall & 0.034 & & & 0.036 & & \\
\hline
\end{tabular}

To further ease the interpretation of the interaction, and to examine $\mathrm{H}_{3}$ and $\mathrm{H}_{4}$, in Figure 1 I plot the predicted value of autonomy for three values of libertarianism $(-2.5,0$, and +2.5 ) over the range of the threat variable. This figure visualizes how three different groups, defined by their score on the libertarianism scale, respond to threat.

Figure 1 provides further illustrative evidence supporting $\mathrm{H}_{2}$ : at lower levels of threat there is a notable difference in the predicted value of autonomy between those who are more libertarian (libertarianism $=+2.5$ ) and those who are less (libertarianism $=-2.5$ ); this difference gradually decreases over the range of the threat variable. This difference decreases from 0.156 when threat is at its lowest (0) to 0.078 when threat is at its highest (1). 


\begin{tabular}{|c|c|c|c|}
\hline \multicolumn{4}{|c|}{$\begin{array}{l}\text { Table 4: slope on libertarianism } \\
\text { conditional on threat (predicting } \\
\text { autonomy) }\end{array}$} \\
\hline \multirow[b]{2}{*}{ threat } & \multicolumn{3}{|c|}{ libertarianism } \\
\hline & $\beta$ & S.E. & $p$-value \\
\hline 0 & 0.031 & 0.002 & 0.000 \\
\hline 0.2 & 0.028 & 0.001 & 0.000 \\
\hline 0.4 & 0.025 & 0.001 & 0.000 \\
\hline 0.6 & 0.022 & 0.001 & 0.000 \\
\hline 0.8 & 0.019 & 0.001 & 0.000 \\
\hline 1 & 0.016 & 0.001 & 0.000 \\
\hline
\end{tabular}

Figure 1 provides support for $\mathrm{H}_{3} . \mathrm{H}_{3}$ predicts that those with a lower level of libertarianism will demonstrate little, if any, change across the range of threat. Figure 1 illustrates a fairly straight line for those who score at -2.5 on the libertarianism scale. The slope for that group is a non-significant 0.010 (s.e. $=0.006, p=0.071$ ). The more authoritarian demonstrate little change across the range of threat.

$\mathrm{H}_{4}$ predicts a negative slope for those with a relatively high libertarian predisposition: higher levels of reported threat should correspond with lower reported levels of autonomy among those with a higher libertarian predisposition. Figure 1 supports this prediction, illustrating a decrease from 0.560 to 0.492 on the autonomy scale. The slope for this line is a significant -0.067 (s.e. $=0.008, \mathrm{p}<0.001)$.

\section{Choice}

As with autonomy, $\mathrm{H}_{1}$ predicts a positive relationship between libertarianism and choice. Model A in Table 5 speaks to this relationship. In Model A, I regress choice on libertarianism controlling for threat and the noted control variables. Supporting $\mathrm{H}_{1}$, the coefficient on libertarianism is a significant 0.017 indicating that choice increases along with libertarianism. Those who report the highest score on the libertarianism variable are predicted to score 0.17 points ( $17 \%$ of the choice scale) higher than those with the lowest score. 
Dependent Variable: Autonomy Attitudes

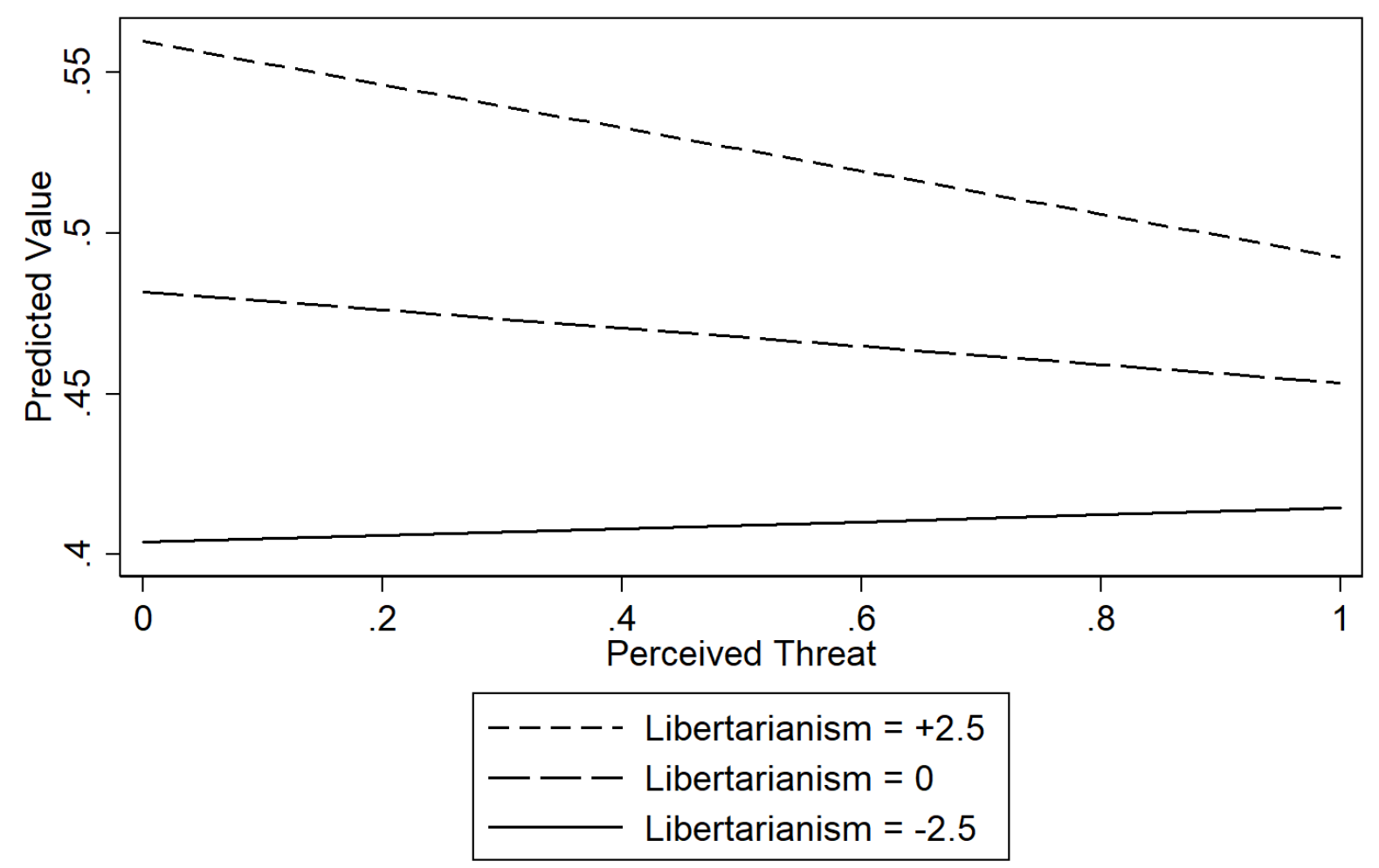

Figure 1: The predicted value of autonomy over the range of threat for three values of libertarianism.

Model B in Table 5 provides evidence for $\mathrm{H}_{2} . \mathrm{H}_{2}$ predicts that the relationship between libertarianism and choice will be weaker when threat is greater. Aligning with this expectation, the coefficient on the interaction is significant and negative, indicating that the slope on libertarianism decreases as threat increases. Table 6 confirms this: higher reported levels of threat correspond with a more gradual slope on libertarianism. The slope at the lowest level of threat is 0.025 , corresponding to an increase of $25 \%$ of the range of the choice scale. The slope at the highest levels of threat is 0.011 , an increase of $11 \%$ of the range of the choice scale.

As with Figure 1, Figure 2 supports $\mathrm{H}_{2}$ : at lower levels of threat there is a notable difference in the predicted value of choice between those who are more libertarian and those 
who are less; this difference gradually wanes over the range of the threat variable. This difference decreases from 0.124 when threat is at its lowest to 0.054 when threat is at its highest.

\begin{tabular}{|c|c|c|c|c|c|c|}
\hline & \multicolumn{3}{|c|}{ model A } & \multicolumn{3}{|c|}{ model B } \\
\hline & $\beta$ & S.E. & $p$-value & $\beta$ & S.E. & $p$-value \\
\hline libertarianism & 0.017 & 0.001 & 0.000 & 0.025 & 0.001 & 0.000 \\
\hline threat & -0.044 & 0.003 & 0.000 & -0.053 & 0.003 & 0.000 \\
\hline libertarianism $X$ threat & -- & -- & -- & -0.014 & 0.002 & 0.000 \\
\hline age & -0.001 & 0.000 & 0.000 & -0.001 & 0.000 & 0.000 \\
\hline education & 0.015 & 0.001 & 0.000 & 0.015 & 0.001 & 0.000 \\
\hline female & 0.024 & 0.002 & 0.000 & 0.024 & 0.002 & 0.000 \\
\hline income & 0.006 & 0.000 & 0.000 & 0.006 & 0.000 & 0.000 \\
\hline constant & 0.286 & 0.014 & 0.000 & 0.290 & 0.014 & 0.000 \\
\hline n (countries) & 54 & & & 54 & & \\
\hline average $\mathrm{n}$ (individuals) per country & 1165.3 & & & 1165.3 & & \\
\hline$r^{2}$ within & 0.048 & & & 0.049 & & \\
\hline$r^{2}$ between & 0.222 & & & 0.250 & & \\
\hline$r^{2}$ overall & 0.060 & & & 0.063 & & \\
\hline
\end{tabular}

Figure 2 provides some evidence for $\mathrm{H}_{3} . \mathrm{H}_{3}$ predicts that those with a lower level of libertarianism will demonstrate little, if any, change across the range of threat. Figure 2 illustrates a fairly straight line for those who indicate a low level of libertarianism. However, the slope for that group is a significant -0.018 (s.e. $=0.005, p<0.000)$ indicating that the line is not quite flat and that an increase in threat does predict a very slight decline in the choice scores of those who score at -2.5 on the libertarianism measure.

$\mathrm{H}_{4}$ predicts a negative slope for those with a relatively high libertarian predisposition: higher levels of reported threat should correspond with lower scores on choice among those with a higher score on libertarianism. Figure 2 supports this prediction, illustrating a decrease 
from 0.417 to 0.329 on the choice scale. The slope for this line is a significant -0.088 (s.e. $=$ 0.006, $p<0.000)$.

\begin{tabular}{lccc}
\hline \hline $\begin{array}{l}\text { Table 6: slope on libertarianism } \\
\text { conditional on threat (predicting } \\
\text { choice) }\end{array}$ \\
\hline \multicolumn{4}{c}{ libertarianism } \\
\cline { 2 - 4 } threat & $\beta$ & S.E. & p-value \\
\hline 0 & 0.025 & 0.001 & 0.000 \\
0.2 & 0.022 & 0.001 & 0.000 \\
0.4 & 0.019 & 0.001 & 0.000 \\
0.6 & 0.016 & 0.001 & 0.000 \\
0.8 & 0.014 & 0.001 & 0.000 \\
1 & 0.011 & 0.001 & 0.000 \\
\hline
\end{tabular}

Dependent Variable: Choice Attitudes

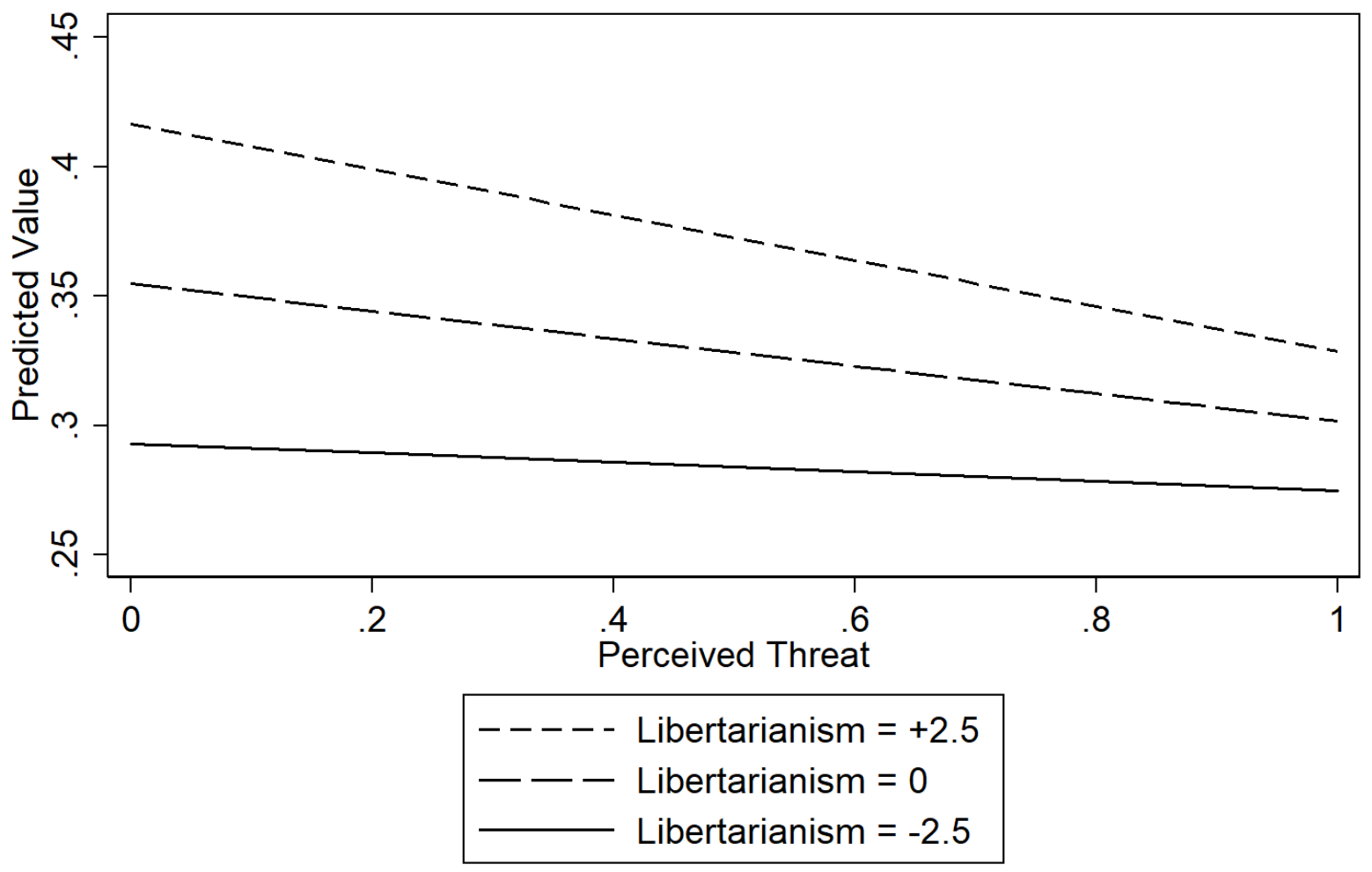

Figure 2: The predicted value of choice over the range of threat for three values of libertarianism. 


\section{Equality}

$\mathrm{H}_{1}$ predicts a positive relationship between libertarianism and equality. Model A in Table 7 substantiates this prediction. Supporting $\mathrm{H}_{1}$, in Model A the coefficient on libertarianism is a significant 0.004 indicating that equality increases along with libertarianism. Those who report the highest score on the libertarianism variable are predicted to score 0.04 points ( $4 \%$ of the equality scale) higher than those with the lowest score. One should note however, that this relationship is substantially weaker than the relationship between libertarianism and either autonomy or choice (or, as we will see, voice).

\begin{tabular}{|c|c|c|c|c|c|c|}
\hline & \multicolumn{3}{|c|}{ model A } & \multicolumn{3}{|c|}{ model B } \\
\hline & $\beta$ & S.E. & $p$-value & $\beta$ & S.E. & $\mathrm{p}$-value \\
\hline libertarianism & 0.004 & 0.001 & 0.000 & 0.010 & 0.001 & 0.000 \\
\hline threat & -0.012 & 0.003 & 0.000 & -0.019 & 0.004 & 0.000 \\
\hline libertarianism $X$ threat & -- & -- & -- & -0.011 & 0.002 & 0.000 \\
\hline age & -0.001 & 0.000 & 0.000 & -0.001 & 0.000 & 0.000 \\
\hline education & 0.024 & 0.001 & 0.000 & 0.024 & 0.001 & 0.000 \\
\hline female & 0.105 & 0.002 & 0.000 & 0.105 & 0.002 & 0.000 \\
\hline income & 0.001 & 0.001 & 0.042 & 0.001 & 0.001 & \\
\hline constant & 0.455 & 0.014 & 0.000 & 0.458 & 0.014 & 0.000 \\
\hline n (countries) & 54 & & & 54 & & \\
\hline average $\mathrm{n}$ (individuals) per country & 1165.3 & & & 1165.3 & & \\
\hline$r^{2}$ within & 0.065 & & & 0.065 & & \\
\hline$r^{2}$ between & 0.145 & & & 0.154 & & \\
\hline$r^{2}$ overall & 0.069 & & & 0.070 & & \\
\hline
\end{tabular}

$\mathrm{H}_{2}$ predicts that the relationship between libertarianism and equality will be weaker when threat is greater. In Model B of Table 7, the coefficient on the interaction is significant and negative, indicating that the slope on libertarianism decreases as threat increases. Table 8 , confirms this: higher reported levels of threat correspond with a more gradual slope on 
libertarianism to the point where the slope loses significance all together. The slope at the lowest level of threat is 0.010 , corresponding to an increase of $10 \%$ of the range of the equality scale. The slope at the highest levels of threat is effectively zero, indicating no difference between those who score at the highest and lowest points on the libertarianism scale.

\begin{tabular}{lccc}
\hline \hline $\begin{array}{l}\text { Table 8: slope on libertarianism } \\
\text { conditional on threat (predicting } \\
\text { equality) }\end{array}$ \\
\hline & \multicolumn{3}{c}{ libertarianism } \\
\cline { 2 - 4 } threat & $\beta$ & S.E. & p-value \\
\hline 0 & 0.010 & 0.001 & 0.000 \\
0.2 & 0.008 & 0.001 & 0.000 \\
0.4 & 0.006 & 0.001 & 0.000 \\
0.6 & 0.003 & 0.001 & 0.000 \\
0.8 & 0.001 & 0.001 & 0.199 \\
1 & -0.001 & 0.001 & 0.275 \\
\hline
\end{tabular}

As with our previous figures, Figure 3 supports $\mathrm{H}_{2}$ : at lower levels of threat there is a significant, if not very substantial, difference in the predicted value of equality between those who are more libertarian and those who are less; as with our previous DVs, this difference gradually wanes over the range of the threat variable, decreasing from 0.051 when threat is at its lowest to 0.006 when threat is at its highest.

$\mathrm{H}_{3}$ predicts that those with a lower level of libertarianism will demonstrate little, if any, change across the range of threat. Figure 3 illustrates a fairly straight line for those who score at the -2.5 mark on the libertarianism scale. The slope for that group is a non-significant 0.009 (s.e. $=0.005, p=0.073)$ indicating an effectively flat line.

$\mathrm{H}_{4}$ predicts a negative slope for those with a relatively high libertarian predisposition. Figure 3 supports this prediction, illustrating a decrease from 0.614 to 0.566 on the equality scale. The slope for this line is a significant -0.048 (s.e. $=0.007, p<0.000)$. 
Dependent Variable: Equality Attitudes

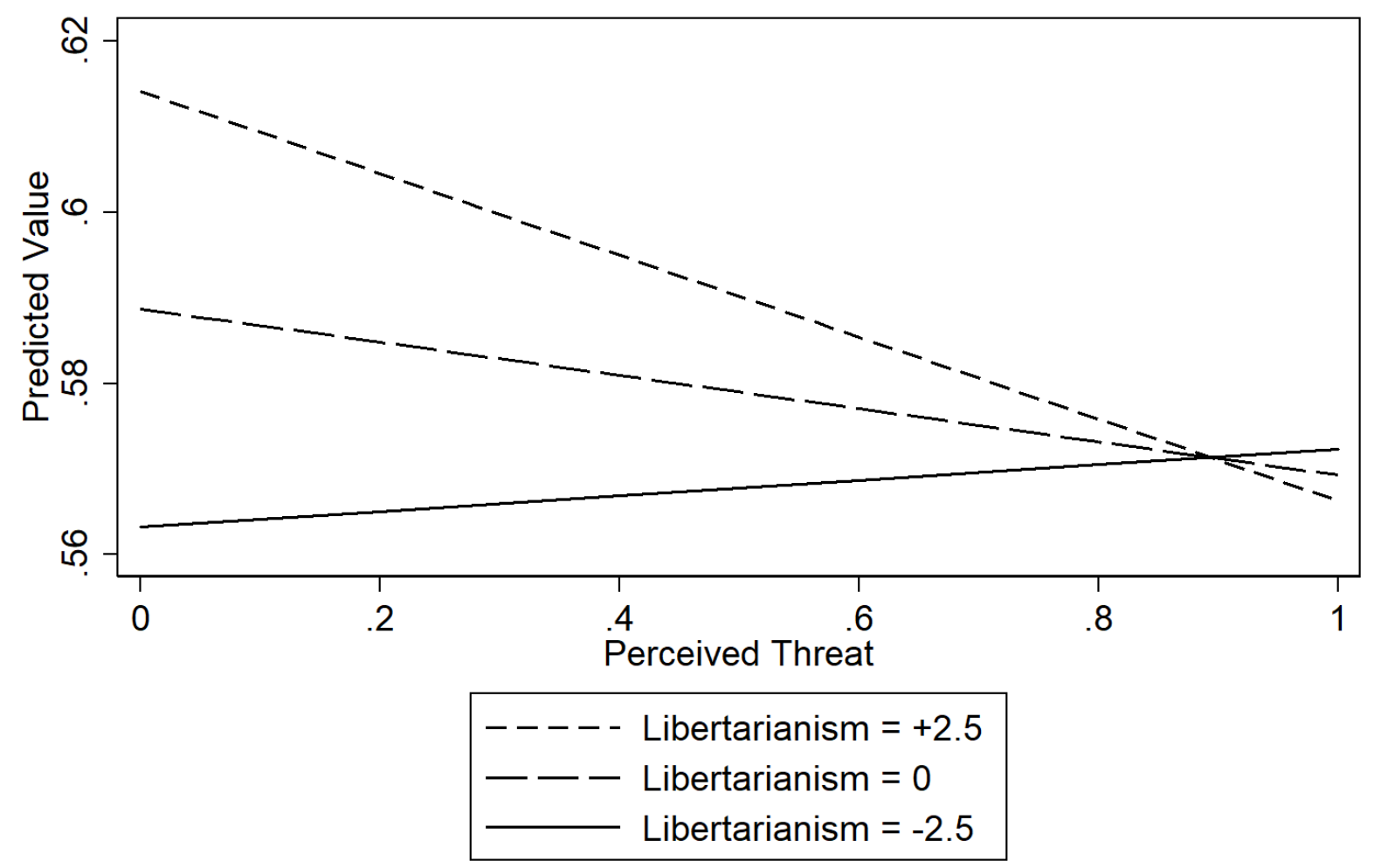

Figure 3: The predicted value of equality over the range of threat for three values of libertarianism.

\section{Voice}

$\mathrm{H}_{1}$ predicts a positive relationship between libertarianism and voice. Model A in Table 8 supports this prediction. In Model A the coefficient on libertarianism is a significant 0.010 demonstrating that voice increases as libertarianism increases. Those scoring highest on libertarianism are predicted to score 0.10 points ( $10 \%$ of the voice scale) higher than those with the lowest score.

$\mathrm{H}_{2}$ predicts that the relationship between libertarianism and voice will be weaker at higher levels of threat. In Model B of Table 9, the coefficient on the interaction is significant and negative, indicating that the slope on libertarianism decreases as threat increases. Table 10 confirms this: higher reported levels of threat correspond with a more gradual slope on 
libertarianism. The slope at the lowest level of threat is 0.016 , corresponding to an increase of $16 \%$ of the range of the voice scale. The slope at the highest levels of threat is 0.006 , corresponding with a $6 \%$ increase in the range of the voice scale.

\begin{tabular}{|c|c|c|c|c|c|c|}
\hline & \multicolumn{3}{|c|}{ model A } & \multicolumn{3}{|c|}{ model B } \\
\hline & $\beta$ & S.E. & $p$-value & $\beta$ & S.E. & $p$-value \\
\hline libertarianism & 0.010 & 0.001 & 0.000 & 0.016 & 0.001 & 0.000 \\
\hline threat & -0.005 & 0.004 & 0.195 & -0.011 & 0.004 & 0.004 \\
\hline libertarianism $X$ threat & -- & -- & -- & -0.010 & 0.002 & 0.000 \\
\hline age & -0.001 & 0.000 & 0.000 & -0.001 & 0.000 & 0.000 \\
\hline education & 0.012 & 0.001 & 0.000 & 0.012 & 0.001 & 0.000 \\
\hline female & 0.003 & 0.002 & 0.210 & 0.003 & 0.002 & 0.207 \\
\hline income & 0.000 & 0.001 & 0.881 & 0.000 & 0.001 & 0.849 \\
\hline constant & 0.317 & 0.012 & 0.000 & 0.320 & 0.012 & 0.000 \\
\hline n (countries) & 54 & & & 54 & & \\
\hline average $\mathrm{n}$ (individuals) per country & 1165.3 & & & 1165.3 & & \\
\hline$r^{2}$ within & 0.014 & & & 0.014 & & \\
\hline$r^{2}$ between & 0.043 & & & 0.047 & & \\
\hline$r^{2}$ overall & 0.014 & & & 0.015 & & \\
\hline
\end{tabular}

Figure 4 supports $\mathrm{H}_{2}$ : at lower levels of threat there is a significant difference in the predicted value of voice between those who are more libertarian and those who are less; as with the previous DVs, this difference gradually wanes over the range of the threat variable. This difference decreases from 0.078 when threat is at its lowest to 0.030 when threat is at its highest.

$\mathrm{H}_{3}$ predicts that those with a lower level of libertarianism will demonstrate little, if any, change across the range of threat. As with the previous DV, equality, this is not precisely the case with voice. Figure 4 illustrates a slightly upwardly oriented line for those who score at the -2.5 mark on the libertarianism scale. The slope for that group is a significant, if not 
very substantial, 0.014 (s.e. $=0.005, p=0.008$ ). This manifests as an increase in the predicted value of voice from 0.311 at the lowest level of threat to 0.325 at the highest.

\begin{tabular}{|c|c|c|c|}
\hline $\begin{array}{l}\text { Table } \\
\text { condit }\end{array}$ & $\begin{array}{l}\text { ope on } \\
\text { on thr }\end{array}$ & $\begin{array}{l}\text { ertari } \\
\text { (pred }\end{array}$ & im voice) \\
\hline & & ertarian & \\
\hline threat & $\beta$ & S.E. & $p$-value \\
\hline 0 & 0.016 & 0.001 & 0.000 \\
\hline 0.2 & 0.014 & 0.001 & 0.000 \\
\hline 0.4 & 0.012 & 0.001 & 0.000 \\
\hline 0.6 & 0.010 & 0.001 & 0.000 \\
\hline 0.8 & 0.008 & 0.001 & 0.000 \\
\hline 1 & 0.006 & 0.001 & 0.000 \\
\hline
\end{tabular}

Dependent Variable: Voice Attitudes

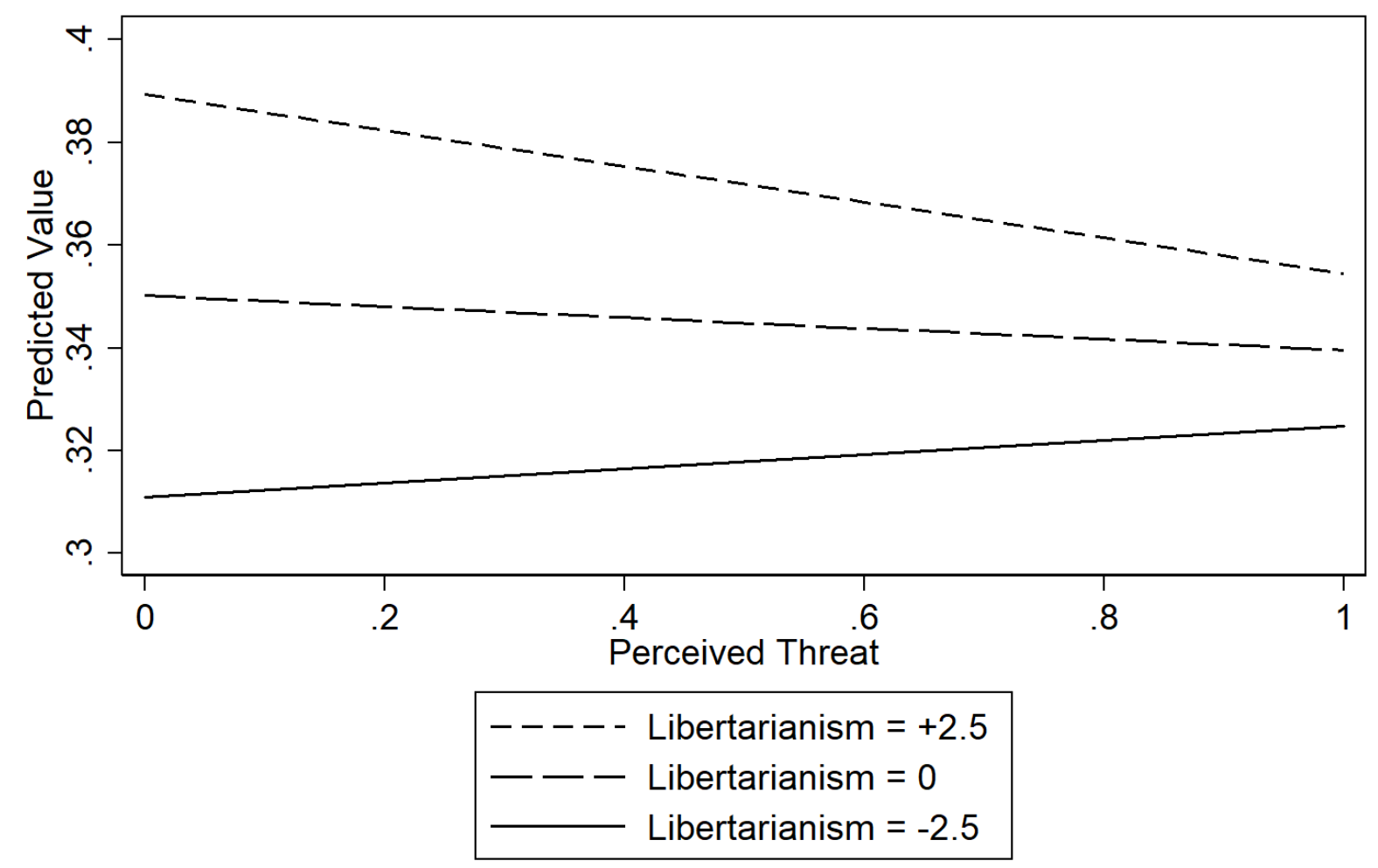

Figure 4: The predicted value of voice over the range of threat for three values of libertarianism. 
$\mathrm{H}_{4}$ predicts a negative slope for those with a relatively high libertarian predisposition and Figure 4 supports this prediction. The slope for this line is a significant, though not very substantial, -0.035 (s.e. $=0.007, p<0.001$ ) corresponding with a decrease in the predicted value of voice from .389 when threat is at its lowest to 0.354 when at its highest.

\section{Discussion}

Dunn et al. (2017) provides argumentation and some initial evidence in support of integrating the concept of authoritarianism into Welzel's (2013) Human Empowerment Sequence. However, due to data limitations they were unable to examine what has become an important consideration in the authoritarianism literature and one of the primary benefits they argue to stem from their theoretical integration: whether and how threat moderates the relationship between libertarianism and emancipative attitudes. This is the task we undertake in this paper.

The analyses in this paper, drawing on data from 54 countries from the sixth wave of the World Values Survey, regresses the four sub-indices of the emancipative attitudes scale, autonomy, choice, equality, and voice, on the interaction between libertarianism and threat, controlling for age, education, gender, and income. The output for this set of multi-level models and a nuanced consideration of the interaction effects between libertarianism and perceived threat supports those expectations derivable from Dunn et al.'s (2017) theoretical reconstruction; threat moderates the relationship between authoritarianism-libertarianism and emancipative attitudes.

The analyses provide a handful of relevant findings. Generally, the more libertarian are more expressive of more emancipative attitudes. This relationship is, however, conditional on perceived threat. The relationship between libertarianism and the emancipative attitudes sub-indices is much stronger, predicting a much wider gap between the more and 
less libertarian, where perceived threat is minimal. As perceived threat increases, the predicted gap between the emancipative attitudes of the more and less libertarian decreases notably. Importantly, this decrease in relational strength is primarily driven by those with a more libertarian predisposition. In other words, those with an authoritarian predisposition hold remarkably similar emancipative attitudes regardless of how much threat they reportedly perceive. Those with a libertarian predisposition, on the other hand, express notably lower levels of emancipative attitudes at higher levels of perceived threat than at lower levels indicating that the attitudes of libertarians move toward those of authoritarians when the more libertarian perceive threat. These findings align comfortably with Dunn at al.'s (2017) adjustment to Welzel's (2013) theory as well as with Hetherington and Weiler's (2009) adjustment to Stenner's (2005) theory of the authoritarian dynamic.

While the pattern is generally the same across all four subscales, the substantive impact is quite different. This can be seen in the coefficient on libertarianism in Model A of Tables 2, 4, 6, and 8. Libertarianism demonstrates the strongest relationship with autonomy, followed by choice, voice, and then equality. Given that the first three measures conceptually coincide with the idea of individual autonomy, it is not surprising that they demonstrate the strongest relationships. One must also consider that of all Welzel's (2013) measures, the autonomy measure is the only one that Dunn et al. (2017) consider to be a convincing measure of values, as opposed to being a measure of attitudes. Welzel's measure of autonomy, is also similar to a previously used measure of the authoritarian disposition (e.g., Dunn, 2014, 2015; Dunn \& Singh, 2011, 2014; Stenner, 2005). This particular model is therefore effectively using one measure of the authoritarian predisposition to predict another, a strong relationship is to be expected. It is also unsurprising that equality shows a much weaker relationship with the authoritarian predisposition given evidence that equality is a value distinct from either individual autonomy or social conformity values (e.g., Schwartz, 
2012). These two emancipative sub-indices exempted, our models predict a substantial change in people's attitudes toward choice and voice: when people perceive threat, they are, as a collective, less supportive of individual choice and voice, two critical aspects of modern liberal democracy.

Previous work such as that of Welzel (2013) and Dunn et al. (2017) at least partially explain the origins of societal differences in the distribution of value orientations and valuerelevant attitudes. The findings in this research provide insight into how perceived threat alters the attitudes and potentially the policy preferences of societies as a whole. As already noted by Hetherington and colleagues (Hetherington \& Suhay, 2011; Hetherington \& Weiler, 2009) in the context of the United States, an increase in the average level of perceived threat can have a notable impact on the distribution of attitudes in a society, particularly when that threat is perceived by more libertarian individuals. Though this threat may only be temporary, it takes little time for motivated parliaments and governments to pass what may be normally unacceptable policies into law. The combination of value orientations and perceived threat can help us to explain societal differences and similarities in the distribution of attitudes and policy preferences as well as how those societies socially and politically respond to perceived threat among their populace.

The interaction of value orientations and perceived threat may also influence the outcome of elections. Singh and Dunn (2015) investigate the relative political participation of authoritarians and libertarians across countries. Their findings suggest that when threatened, the participation rates of libertarians can drop to equal those of authoritarians (who are generally less participatory). Authoritarians, on the other hand, remain rather steady regardless of threat. The authors conclude that because of this dynamic, under conditions of threat the rate of participation among authoritarians increases relative to the population as a whole, giving this group increased weight overall. Combining these findings with our 
conclusions in this paper suggests two different pathways in which authoritarian expression may affect voting outcomes: via an increased proportion of authoritarian voters and via increased authoritarian (non-emancipative) expression from the more libertarian. This combination of factors may explain the increased support that more authoritarian parties (cf., Dunn \& Singh, 2011) are currently enjoying in various European countries (e.g., the Party for Freedom in the 2017 Dutch general election, the National Front in the 2017 French presidential elections, the Alternative for Germany in the 2017 German federal elections, the Fidesz-KDNP alliance in the 2018 Hungarian parliamentary elections, Lega in the 2018 Italian general election) (though see Dunn, 2015).

Importantly, in combination with previous research in the areas of political culture and individual-level authoritarianism, this paper explains differences in the distribution of individual attitudes and public opinion more generally by reference to political culture. While suggesting that political culture impacts public opinion is not a novel claim, this paper indicates that social and political attitudes are not a simple reflection of political culture but the result of the interaction between political culture and contemporary social and political events that may threaten the psychological or physical wellbeing of those in society. Expressed public opinion must not be considered a direct reflection of political culture, but a moderated expression of such that may result more from perceived threat, than from a deeply ingrained set of values specific to that country.

As with all cross-national cross-sectional studies, we stress the need for caution when interpreting the results presented here. While these results are consistent with the intrapersonal change theorized, there is, of course, no actual evidence of intra-personal change. Ideally in a study such as this, one would look at change in individuals over time to examine whether changes in threat precede and correspond with changes in emancipative attitudes for libertarians while similar changes in threat do little to change the emancipative attitudes of 
authoritarians. Given the lack of wide-ranging cross-national, individual-level, longitudinal data, this is unfortunately out of reach at present. For the time being we will have to rely on longitudinal analyses in single country studies, such as that provided by Hetherington and Weiler (2009), to provide causal support to our cross-national, cross-sectional studies.

An additional problem with cross-sectional work is our inability to comment on the changing (or not) relationship between political culture and political institutions. A single cross-sectional study cannot comment on this potentially evolving relationship. This research provides evidence that perceived threat does indeed impact those attitudes that, in the aggregate, others have found to be important for the waxing and waning of democracy (e.g., Inglehart \& Welzel, 2005; Welzel, 2013). An important question at this stage, then, is whether the relationship between values and institutions is more vital to the regression or progression of democracy that the relationship between attitudes and institutions. In other words: can a temporary shift in attitudes in response to perceived threat destabilize otherwise stable democratic institutions or is a more fundamental shift in values necessary? 
References:

Adorno, T. W., Frenkel-Brunswik, E., Levinson, D. J., \& Sanford, R. N. (1950). The authoritarian personality (1st ed.). New York: Harper.

Alemán, J., \& Woods, D. (2016). Value Orientations From the World Values Survey: How Comparable Are They Cross-Nationally? Comparative Political Studies, 69(8), 10391067.

Almond, G. A., \& Verba, S. (1963). The Civic Culture: Political attitudes and democracy in five nations. Newbury Park, Calif.: Sage Publications.

Altemeyer, B. (1981). Right-Wing Authoritarianism. Winnipeg: University of Manitoba Press.

Altemeyer, B. (1988). Enemies of Freedom: Understanding right-wing authoritarianism (1st ed.). San Francisco: Jossey-Bass Publishers.

Altemeyer, B. (1996). The authoritarian specter. Cambridge, MA: Harvard University Press.

Banaji, M. R., \& Heiphetz, L. (2010). Attitudes. In S. T. Fiske, D. T. Gilbert \& G. Lindzey (Eds.), The handbook of social psychology (5th ed., Vol. 1). Hoboken, N.J.: John Wiley.

Daniel, E., Fortuna, K., Thrun, S. K., Cioban, S., \& Knafo, A. (2013). Brief report: Early adolescents' value development at war time. Journal of Adolescence, 36(4), 651-655.

Davidov, E., Meuleman, B., Cieciuch, J., Schmidt, P., \& Billiet, J. (2014). Measurement Equivalence in Cross-National Research. Annual Review of Sociology, 40(1), 55-75.

Dunn, K. (2014). Authoritarianism and Intolerance Under Autocratic and Democratic Regimes. Journal of Social and Political Psychology, 2(1), 220-241.

Dunn, K. (2015). Preference for Radical Right-wing Populist Parties among Exclusivenationalists and Authoritarians. Party Politics, 21(3), 367-380.

Dunn, K., Griffiths, E., Lamb, S., Shortt, R., \& Theochari, E. (2017). The Human Empowerment Sequence and the Development of Libertarian Values: A Theoretical and Empirical Adjustment to the Human Empowerment Sequence. Journal of CrossCultural Psychology, 48(5), 771-789.

Dunn, K., \& Singh, S. P. (2011). The Surprising Non-impact of Radical Right-wing Populist Party Representation on Public Tolerance of Minorities. Journal of Elections, Public Opinion \& Parties, 21(3), 313-331.

Dunn, K., \& Singh, S. P. (2014). Pluralistic Conditioning: Social tolerance and effective democracy. Democratization, 21(1), 1-28.

Eurofound. (2017). Income Inequalities and Employment Patterns in Europe Before and After the Great Recession. Online.

Feldman, S. (2003). Enforcing social conformity: A theory of authoritarianism. Political Psychology, 24(1), 41-74.

Feldman, S., \& Stenner, K. (1997). Perceived threat and authoritarianism. Political Psychology, 18(4), 741-770.

Frenkel-Brunswik, E., Levinson, D. J., \& Sanford, R. N. (1947). The Antidemocratic Personality. In E. E. Maccoby, T. M. Newcomb \& E. L. Hartley (Eds.), Readings in Social Psychology. New York: Henry Holt \& Co.

Fromm, E. (1941). Escape from freedom. New York: Farrar \& Rinehart.

Halikiopoulou, D., \& Vasilopoulou, S. (2016). Breaching the Social Contract: Crises of Democratic Representation and Patterns of Extreme Right Party Support. Government and Opposition, 53(1), 26-50.

Hetherington, M. J., \& Suhay, E. (2011). Authoritarianism, threat, and Americans' support for the War on Terror. American Journal of Political Science, 55(3), 546-560. 
Hetherington, M. J., \& Weiler, J. D. (2009). Authoritarianism and Polarization in American Politics. Cambridge; New York: Cambridge University Press.

Hitlin, S., \& Piliavin, J. A. (2004). Values: Reviving a Dormant Concept. Annual Review of Sociology, 30, 359-393.

Hox, J. J., Moerbeek, M., \& Schoot, R. v. d. (2018). Multilevel Analysis: Techniques and applications (Third ed.).

Inglehart, R. (1971). The Silent Revolution in Europe: Intergenerational Change in PostIndustrial Societies. The American Political Science Review, 65(4), 991-1017.

Inglehart, R. (1977). The Silent Revolution: Changing values and political styles among Western publics. Princeton, N.J.: Princeton University Press.

Inglehart, R. (1988). The Renaissance of Political Culture. The American Political Science Review, 82(4), 1203-1230.

Inglehart, R. (1990). Culture shift in advanced industrial society. Princeton, NJ: Princeton University Press.

Inglehart, R. (1997). Modernization and Postmodernization: Cultural, economic, and political change in 43 societies. Princeton, N.J.: Princeton University Press.

Inglehart, R. (2017). Evolutionary Modernization Theory: Why People's Motivations are Changing. Changing Societies \& Personalities, 1(2), 136-151.

Inglehart, R., Haerpfer, C., Moreno, A., Welzel, C., Kizilova, K., Medrano, J. D., . . . Puranen, B. (2014). World Values Survey: Round Six - Country-Pooled Datafile 20102014.

Inglehart, R., \& Welzel, C. (2005). Modernization, cultural change, and democracy: The human development sequence. New York, NY: Cambridge University Press.

Institute for Fiscal Studies. (2017). Historically weak growth in living standards set to continue; low-income households with children to fare worst. Online.

Kaplan, K. J. (1972). On the ambivalence-indifference problem in attitude theory and measurement: A suggested modification of the semantic differential technique. Psychological Bulletin, 77(5), 361-372.

Lipset, S. M. (1959). Democracy and Working-Class Authoritarianism. American Sociological Review, 24(4), 482-501.

Lönnqvist, J.-E., Jasinskaja-Lahti, I., \& Verkasalo, M. (2011). Personal Values Before and After Migration:A Longitudinal Case Study on Value Change in Ingrian-Finnish Migrants. Social Psychological and Personality Science, 2(6), 584-591.

McCoy, J., Rahman, T., \& Somer, M. (2018). Polarization and the Global Crisis of Democracy: Common Patterns, Dynamics, and Pernicious Consequences for Democratic Polities. American Behavioral Scientist, 62(1), 16-42.

Norris, P., \& Inglehart, R. (2019). Cultural Backlash: Trump, Brexit, and Authoritarian Populism. Cambridge: Cambridge University Press.

Raviv, A., Sadeh, A., Raviv, A., Silberstein, O., \& Diver, O. (2000). Young Israelis' Reactions to National Trauma: The Rabin Assassination and Terror Attacks. Political Psychology, 21(2), 299-322.

Schwartz, S. H. (2012). An Overview of the Schwartz Theory of Basic Values. Online Readings in Psychology and Culture, 2(1), 1-20.

Singh, S. P., \& Dunn, K. (2013). Veto players, the policymaking environment, and the expression of authoritarian attitudes. Political Studies, 61(1), 119-141.

Singh, S. P., \& Dunn, K. (2015). Authoritarianism, socioethnic diversity and political participation across countries. European Journal of Political Research, 54(3), 563 581.

Sokolov, B. (2018). The Index of Emancipative Values: Measurement Model Misspecifications. American Political Science Review, 1-14. 
Sortheix, F. M., Parker, P. D., Lechner, C. M., \& Schwartz, S. H. (2017). Changes in Young Europeans' Values During the Global Financial Crisis. Social Psychological and Personality Science.

Steenkamp, J.-B. E. M., \& Baumgartner, H. (1998). Assessing Measurement Invariance in Cross-National Consumer Research. Journal of Consumer Research, 25(1), 78-107.

Stenner, K. (2005). The Authoritarian Dynamic. New York, NY: Cambridge University Press.

Verkasalo, M., Goodwin, R., \& Bezmenova, I. (2006). Values Following a Major Terrorist Incident: Finnish Adolescent and Student Values Before and After September 11, 2001. Journal of Applied Social Psychology, 36(1), 144-160.

Welzel, C. (2013). Freedom Rising: Human empowerment and the quest for emancipation. New York, NY: Cambridge University Press.

Welzel, C., \& Inglehart, R. F. (2016). Misconceptions of Measurement Equivalence: Time for a Paradigm Shift. Comparative Political Studies. 
